\title{
Overseas Communication of English Translation of The Book of Rites from the Perspective of Translation-communication Model
}

\author{
Yuefan Wu ${ }^{1,2}$, Junping Liu ${ }^{1}$ \\ ${ }^{1}$ Translation and Interpreting Department, Wuhan University, Wuhan, PR China \\ ${ }^{2}$ Translation and Interpreting Department, Hubei University of Science and Technology, Xianning, PR China
}

Email address:

70904097@qq.com(Yuefan Wu)

\section{To cite this article:}

Yuefan Wu, Junping Liu. Overseas Communication of English Translation of The Book of Rites from the Perspective of

Translation-communication Model. International Journal of Applied Linguistics and Translation. Vol. 5, No. 3, 2019, pp. 41-47.

doi: $10.11648 /$ j.ijalt.20190503.12

Received: August 10, 2019; Accepted: August 28, 2019; Published: September 11, 2019

\begin{abstract}
Chinese culture has gone through many stages of overseas communication before the contemporary call for its going-out. The Book of Rites, as an indispensable part of Chinese culture, has also experienced ups and downs in the circulation. A comprehensive diachronic collation of the communication history of The Book of Rites is helpful for acquiring effective lessons and inspirations from the ups or efficient communication, on which there has not enough systematic research. Therefore, this thesis wants to initiate the specialized research of The Book of Rites on its communication by answering the following questions from the translation-communication angle: What is the historical process of English translation of The Book of Rites? What were communication realities of English versions of The Book of Rites in different historical periods? The answers are: the overseas communication of English versions of The Book of Rites has gone through 3 stages from initial introduction stage from the second half of the 19th century to the beginning of the $20^{\text {th }}$ century, to the gold development of brief translation in the $20^{\text {th }}$ century, and to the cold reception of reprinting of excerption and retranslation in the $21^{\text {st }}$ century. The change from the efficient communication to cold reception urges us to reverse the trend, which has got some resolution possibilities from Lasswell's communication model that the overseas translators and sinologists should join hands with Chinese native scholars to trans-feel the original idea for overseas readers, and take overseas platforms to achieve the maximum conductance or equivalence to realize efficient communication.
\end{abstract}

Keywords: The Book of Rites, Overseas Communication, Translation-communication Model

\section{Introduction}

The Book of Rites, as an important part of Chinese classics, embodies the spiritual values and early institutional concepts of Chinese nation. However, the systematic study of overseas communication of English translation of The Book of Rites at home and abroad has matched with its importance, since the relevant studies concentrate on the text analysis [1-9], cultural conceptions [10-12] or the style of Legge's translation [13], the comparison of Legge's and An's versions [14, 15], translation history as a part of the Five Classics [16]. Therefore, the research on overseas communication of English translation of The Book of Rites from the perspective of translation-communication model is a new perspective. The research is initiated by the analysis on historical communication process to gain some suggestions for efficient communication and effective reception.

The overseas communication of The Book of Rites originated from its translation from the $16^{\text {th }}$ century. The English translation began from the $19^{\text {th }}$ century with James Legge's version in 1885 as a typical symbol. The full translation of The Book of Rites only witnesses two versions, including Luo Zhiye's besides Legge's, the rest are brief translations, including Arthur Waley's, Giles's in A History of Chinese Literature, Lin Yutang's in The Wisdom of Confucius, An Zengcai's reconstruction. Different translations met different receptions attributed to distinctive communication elements including environment, aims, subjects, content 
choice, media and audience. Legge's version met the needs of the readers who wanted to know China under the environment of China's initial opening to the outside world. Giles's selected translation, as a part of Chinese classics, was aimed at introducing the history of Chinese literature. Lin took the selected translation as a part of the essence of Confucianism to highlight the wisdom of Confucius, inspiring English readers and hence gaining the most popularity. An's and Luo's were the results responding to the environment of "Chinese culture going-out" centering on lateral export without enough attention on readers' needs, whose communication effect was not satisfactory.

In summary, the overseas communication of English versions of The Lî Kî or The Book of Rites has gone through 3 stages from initial introduction to gold development to cold reception: introduction stage from the second half of the 19th century to the beginning of the $20^{\text {th }}$ century; brief translation stage in the $20^{\text {th }}$ century; reprinting of excerption and retranslation stage in the $21^{\text {st }}$ century.

\section{Overseas Communication of The Book of Rites from the Perspective of Translation-communication Model}

Translation and communication constitute an intimate relationship, similar to Newmark's communicative translation theory [17], Wilss's message delivery of translation [18], Lv Jun's translation-communication concept that "translation studies is a special field of communication studies" [19], Liao Qiyi's translation information theory [20], Xie Ke and Liao Xueru's proposed "translation-communication theory" [21]. There is a necessity to put an eye on translation from the perspective of communication. Hence, translation-communication model introduced the communication model put forward by Harold Lasswell including communicators, content, media, audiences, effect. As a seemingly unidirectional description of the communication model, Lasswell gave a bidirectional concept, i.e., communication is not only a process from communicator to audiences or to effect but also vice versa. The elements constitute a communication net rather than a line. Domestic scholars Xie Ke and Liao Xueru [21] added two more elements: aim and environment.

\subsection{Communication Aim and Communicators}

Communicators are subjects with aims. Lasswell [22] divided three categories of "specialists" in the process of communication, who are also communicators: the group who "surveys the political environment", the group who "correlates the response" "to the environment", the group who "transmits certain patterns of response from the old to the young", corresponding to (1) patrons, mainstream ideology, diplomats, foreign media; (2) publishing houses, domestic media, critics, audiences, translators; (3) education organizations, educators, scholars. Some group members could play two roles in two groups, such as translators, who could respond to the call or demand of the environment to finish the text choice as the role (2) while choose the classical literature to perform retranslation to realize the inheritance i.e. the role in group (3). So are the critics who respond to a translation field or environment to trigger a hot discussion of the version to give a new life to the translated text, inheriting in another form and way. The division is helpful to distinguish and recognize each group and their roles but not to distinctively divide them, for every communication performance is the result of their common efforts.

At the first stage of translation and communication of The Book of Rites in the second half of the $19^{\text {th }}$ century, Christian missionaries came to China to serve the mission and to strengthen the religion ties with China, boosting them to the major communicators. Therefore, the English translation of Chinese cultural classics which was thought to embody certain god-related concepts culminated consisting of the main books of Confucianism, Buddhism and Taoism, among which The Book of Rites occupied an irreplaceable position. Legge, the "scholarly translator" and one of major communicators, performed different roles as a "missionary-educator-scholar" [23]. The major communicators of The Book of Rites were missionaries, diplomats in group (1) and sinologists in group (3).

In the $20^{\text {th }}$ century, overseas sinologists and domestic bilingual scholars began to pay attention to Chinese classical literature with specific concern about funeral rites, sacrifice rites, divining, social orders, ethics and politics, education, music, which had become the major selection preferences and major translation and communication content under the help of publishing presses. The translation and communication at this stage had no chance to surpass the vital position of Legge's version. Under the communication environment of globalization and world literature, Chinese classical literature attracted some research attentions, which put the introduction-based communication to the fore with the purpose of putting forward cultural exchange and introducing Chinese culture for the first immigrants including ambassadors in group (1) and merchants in group (2) by some cultural communication volunteers, Chinese scholars with bilingual and bi-cultural education background and domestic scholar-translators of dual identities in group (2) and (3) inclined to the sense of cultural inheritance and evolution in line with times.

When it comes to the $21^{\text {st }}$ century, the media including networks, online and offline sales platforms, publishing houses, self-media have become the emerging communicators, whose cooperation with each other and with people along with the people-people and people-technology/ machine co-operations constitute the mainstream of communication. Translation subjects at this phase mainly rely on the full cooperation between Chinese bilingual scholars and English sinologists, while communicators or communication subjects should unify the efforts of patrons, ideological guide-governmental organs, publishing houses, cultural bodies and scholars, translation entities and organizations, civil translation teams and groups. With the arrival of internet plus era, communication has welcomed multivariate and 
multidimensional circulation path. Multivariate communication means that the communication subjects have multiple identities including media, publishing and printing entities, commodity trading entities; multidimension means the media boast different forms including text media, mass media by means of an integrated communication path through computers and mobile internet. Legge's The Lî Kî in 1885 collected in The Sacred Books of China has been transformed from a printed book to electronic scanning web pages by Google as a free source. In 2016, the selected bilingual parallel of The Lî Kîl was republished by Zhongzhou Ancient Books Publishing House and put in Amazon online for sale as the title of The Book of Rites, a selection of some chapters that embodies typical Chinese culture and ensure the attraction of
English readers' attention. Under the communication environment of "Chinese culture going-out" and "telling Chinese stories", the communication of The Book of Rites has stepped into the era of publishing entities, computers and mobile internet as the major communication subjects when the unification of three groups mentioned above has been put into full play.

\subsection{Communication Content}

According to the above description of the communication of The Book of Rites, the communicators and their identities, book titles and forms, publishing presses and time are shown in the following table:

Table 1. Communication Content of The Book of Rites.

\begin{tabular}{|c|c|c|c|c|}
\hline Communicators & Identities & Titles \& Forms & $\begin{array}{l}\text { Publishing } \\
\text { Presses }\end{array}$ & $\begin{array}{l}\text { Publishing } \\
\text { Time }\end{array}$ \\
\hline $\begin{array}{l}\text { James Legge with the aid } \\
\text { of Wang Tao, a Chinese } \\
\text { intellectual }\end{array}$ & $\begin{array}{l}\text { English missionary- } \\
\text { educator-scholar, } \\
\text { sinologist, scholarly } \\
\text { translator }\end{array}$ & The $L \hat{\imath} K \hat{l}$, full translation & $\begin{array}{l}\text { The Clarendon } \\
\text { Press }\end{array}$ & 1885 \\
\hline Herbert G. Giles & English sinologist & $\begin{array}{l}\text { Selected in A History of Chinese Literature as an indispensable } \\
\text { part of Chinese literature }\end{array}$ & $\begin{array}{l}\text { Charles E. Tuttle } \\
\text { Company, Inc. }\end{array}$ & 1901 \\
\hline Lin Yutang & $\begin{array}{l}\text { Chinese writer, } \\
\text { scholarly translator }\end{array}$ & $\begin{array}{l}\text { Selected in The Wisdom of Confucius as the important thoughts } \\
\text { of Confucianism }\end{array}$ & $\begin{array}{l}\text { Random House, } \\
\text { Inc. }\end{array}$ & 1938 \\
\hline An Zengcai \& Xu Chao & $\begin{array}{l}\text { Chinese professor, } \\
\text { scholar }\end{array}$ & $\begin{array}{l}\text { Translations of Confucian Classics: The Book of Rites, } \\
\text { (selections) as a reinterpretation of the original text's division } \\
\text { and concise interlingual conversion }\end{array}$ & $\begin{array}{l}\text { Shandong } \\
\text { Friendship Press }\end{array}$ & 1999 \\
\hline $\begin{array}{l}\text { James Legge } \\
\& \text { Ma Jizhao, Li Liwei }\end{array}$ & $\begin{array}{l}\text { English sinologist \& } \\
\text { Chinese scholars }\end{array}$ & $\begin{array}{l}\text { The Book of Rites, revised selections of The } L \hat{\imath} K \hat{\imath} \text { and parallel } \\
\text { intralingual and interlingual translation }\end{array}$ & $\begin{array}{l}\text { The Clarendon } \\
\text { Press }\end{array}$ & 2016 \\
\hline Luo Zhiye & $\begin{array}{l}\text { Chinese professor, } \\
\text { translator }\end{array}$ & $\begin{array}{l}\text { Seven Sacred Books of China: Li Ji On Propriety [Social and } \\
\text { Individual Behavior], full translation }\end{array}$ & $\begin{array}{l}\text { Southeast } \\
\text { University Press }\end{array}$ & 2017 \\
\hline
\end{tabular}

Giles mentioned some part of "T'an Kun", a chapter of funeral rites. Lin selected some dialogues from "Ru Xing (the conduct of the Ju/scholar)", "Zhongni Yan Ju (Zhongni at home at ease)" and "Qu Li" in "Introduction" part; "Jing Jie (the principle of social order)", "An Interview with Duke Ai", "Li Yun (a vision of a social order)", "On Education", "On Music". An Zengcai, selecting and reconstructing the original content, translated according to Xu Chao's intralingual interpretation and division of 81 sections. Revised selected versions of The Book of Rites gave a common inclination that covers divining for luck, reception ceremonies, military rules, funeral rites, awarding rules, virtue, education, music, wedding, filial piety, gentlemen's conduct, dressing, capping, which were exquisitely chosen, relatively culture-bound and attractive contents. The standard of choice from different translators or publishing houses is decided according to communication environment, patrons, ideology and translator's subjectivity, forming distinctive characteristics from heavy translation to cultural interpretation to conciseness.

Lasswell [22] consented that the concentration of communication may be put "on the analysis of content" subdivided into "the study of purport and style": "the first referring to the message, and the second to the arrangement of the elements of which the message is composed."

The Book of Rites is one of "the three books about Li", and the other two are Zhou Li or The Book of State System of Royal Court in Zhou and Warring States Period and $\mathrm{Yi}$ Li or The Book of Officers'Rites. It is a collection of essays of more than 90,000 words by Confucius disciples and scholars who discussed the ritual systems from the pre-Qin period to the late Warring States Period between 51 B. C. and 21 B. C., consisting of 49 articles covering state systems, ceremonies and rites of the royal court and families, and interpersonal relationships. Some quotations from The Book of Rites have been widely used in other classics. For example, Mencius has cited "Qu Li"or "summary of the rules of propriety" and "Li Qi" or "rules of propriety in the formation of character"; Zhong Yong or The Doctrine of the Mean and Da Xue or The Great Learning were separated from The Book of Rites as two classic works of the Four Books and as the introductory books for reading the Five Classics. In addition, Wu Yunhui [24] proposed to re-understand The Book of Rites from the modern perspective to rejuvenate its ancient wisdom.

Different readers display distinctive interpretations on the same text. Translators, as special readers, are destined to choose different styles to translate. Translation style is mostly decided by the aim and style of the translator. Legge gave the detailed pretext/introduction and notes to fulfill the task of understanding China, which decided the style of heavy translation along with his identity of a scholar and sinologist. Giles and Lin shared a common aim: to choose the parts fitting 
for their books writing, so the style was marked with two writer-translators' subjectivity in selection and reconstruction. An, with the aim of provoking a new life to The Book of Rites, chose the interpretative and reconstructive style. Since Luo wanted to inherit traditional Chinese culture in a modern way, he picked the concise and direct style. No matter what contents and styles have been chosen, they cannot be disseminated without the assistance of communication media.

\subsection{Communication Media}

Communication media analyze the involved communication channels and means including any organization and information carrier for the mass: newspapers, presses home and abroad and the internet.

In the era of printing and newspaper, the introduction of The Book of Rites was accomplished through news serials and printed texts and books. Xie Tianzhen [25] confirmed the media effect of overseas publishing entities. The mentioned The Sacred Books of the East with The Lî Kî collected in was published by London Clarendon Press, and A History of Chinese Literature by New York D. Appleton \& Company.

The development of the internet shapes its role of effective media: Google free web page and amazon online sales channel provided the platforms for English translations of The Book of Rites to be shared worldwide. And the future development of the communication media has been suggested by professor Xie Tianzhen, "The state could set up some special funds for the translation and publishing of Chinese literature, part of which is used for foreign sinologists, translators for their cooperation and contributions of communication, part of which for the establishment of some permanent bases for Chinese-English translation." [25]

\subsection{Communication Audience and Effect}

"Often it is simpler to combine audience and effect analysis... than to keep them apart" [22], for the audience's reaction and feedback would influence the effect, and the effect's results would trigger or ruin the audience's purchase and comment action which will initiate another round of influence. The audience is always regarded as the passive communication subjects, but to the contrary, the audience and communicators constitute a relationship of coexistence or symbiosis, co-configuration and negotiation, which has changed the passive position of the audience. When the audience stands in the center of the communication, the communicators display the passion to "acquire" and "capture" the audience.

Is the translation and communication of The Book of Rites mainly aimed at the reception of the audience? The answer is yes and no. The answer yes tells that the audience's reception decides the communicators' text choice and communication strategies. Without arousing the attraction of the audience, the communication will lost its existence qualification and significance. The answer no means not totally, i.e., the audience's reaction is important but not unique, and there are many other elements that should be attributed to, such as the environment, influence and comments of the media, library collection, circulation, translator's capability.

The Book of Rites was first communicated as one part of the Five Classics. Legge said, “... it would be worthwhile to bring out 'an edition of the Four Books and Five Kings,' the Gospels, as they have been called and Pentateuch of China, accompanied with a translation and notes, which might serve as a standard work to the foreign student of Chinese literature, and lay open to the general reader the philosophy, religion, and morals of that singular people." [23] Therefore, the audience of The Book of Rites in the times of Legge included the foreign learners and sinology enthusiasts having interests in learning Chinese literature, common readers wanting to know Chinese philosophy, religion and morality, besides the missionaries who wanted to get to know China, especially the content related to Christianity. The editor of the revised parallel selection of The Book of Rites gave the following comments on the importance of its communication, "Legge's translations, though having passed over a hundred years, are still regarded as the standard versions of Chinese classics, the significant reference for England and American Chinese teaching, the important texts and carriers for European and American cultural field to have a deep understanding of Chinese traditional culture."

To the first half of the $20^{\text {th }}$ century, Chinese scholars went abroad to get further education and more experiences about the exotic culture, which was helpful for the writer-scholar Lin Yutang to bring his bi-cultural background into full play to take English speaking audience as the communication target, extending the scholar-based audience to common audience. Common audience is more conducive to the communication effect which is the reason why Lin's were among the most popular works.

The period from the second half of the $19^{\text {th }}$ century with the representative of Legge's heavy translation to the beginning of the $20^{\text {th }}$ century with the representative of Lin Yutang's revision was the golden era of the translation and communication of The Book of Rites. And the communication effect is attributive to the high quality versions produced by capable translators while meeting the audience's needs.

In the $21^{\text {st }}$ century, the library collection and sales of revised selections of parallel version is not satisfying. According to OCLC (Online Computer Library Center), the most library collections exist in Chinese mainland, Hong Kong and Taiwan, among which Taiwan has the most. The translation languages mainly include Japanese, French, German, English, among which Japanese versions occupy the most. The communication effect of English versions are not pleasing in English speaking countries. The communication of The Book of Rites is only a unilateral action of China. Another proof is the purchasers who are mostly bilingual learners and scholars for the need of researches.

It is clear that the communication effect has gone through a declining tendency. The reasons behind are multifarious. First, some source countries' senses of national superiority are almost always involved in cross-cultural communication, affecting the effectiveness of communication. The result of mutual exclusion between individuals and cultural groups is 
the failure to achieve meaningful information exchange. Second, the communication of The Book of Rites is also influenced by ideology, including the life experiences, education, ways of thinking, religious ideas of translators, communicators and audiences, and by patrons, such as the government and publishing institutions who would make the choice of literary works going out and representing typical Chinese culture and decide the positioning of communication. Third, the going-out of the English translation of The Book of Rites is mainly the communication of Legge's version without any concern about the retranslation and any other forms beyond printing or electronic books, a little lagging behind the demand of modern times. Finally, the presentation forms of English translation of The Book of Rites fail to meet the demand of the market and the needs of readers to make breakthroughs and innovations. Therefore, the English translation of The Book of Rites is likely to be trapped in a unilateral wish dilemma which is not beneficial for efficient overseas circulation and dissemination.

However, literary works are not merely products that are market-oriented only but a cultural symbol that requires the inheritance from generations to generations. It is the efforts of contemporary translators' retranslation and domestic publishing presses' support that ensure the succession and inheritance of The Book of Rites. Though the modern communication is not compatible to the situation in the second half of the $19^{\text {th }}$ century and the first half of the $20^{\text {th }}$ century, the retranslation, revision and researches are necessary efforts to bring new life to the classics.

\subsection{Communication Environment}

The communication environment of translation mainly explores various environmental factors that affect the communication effect, such as social, political, humanity and economic environment.

The early communication of the English translation of The Book of Rites was under a period when China was subjected to foreign aggression to be forced to open the door. It was in this environment that The Book of Rites has gained an opportunity to spread beyond the territorial boundary.

China then entered the revolutionary and reform period in the $20^{\text {th }}$ century when the works have been circulated from input to output, setting new demands on English translation of Chinese and creating an open environment for the output means. The difficulty of translating The Book of Rites has aroused a consensus of sinologists and domestic scholars. Therefore, there was no breakthrough in full translation at this time, but in brief translation.

By the beginning of the $21^{\text {st }}$ century, China met economic globalization, cultural development, and international cooperation. Overseas sinologists began to turn their attention to modern and contemporary works, covering science fictions and magic and fantasy novels. Then the English translation of The Book of Rites encountered a cold reception.

Furthermore, new media environment has lagged the communication and development of Chinese traditional culture behind the development speed of economic construction. Compared with new media's dependence on leading edge communication technologies and means of popular culture, the communication media of The Book of Rites expose the obvious disadvantages. In addition, pop culture has witness a sudden and sharp rise, making is easier to win the favor of the audience with its close relationship with today's mainstream media such as TV and the Internet, which brings the great challenges and impact to the communication of The Book of Rites. But challenges are always closely related and mutually dependent with opportunities, so some suggestions could be followed according to the requirement of the environment: the loose narratives of The Book of Rites could be sorted according to different themes, and the discourses could be deconstructed and reorganized into texts; the attention could be paid to the translation of the interpretations or the modern re-readings of The Book of Rites; the classical interpretation could be done in a popular way, such as rewriting to historical dramas around the topics of overseas audience's interests, or a multimodal presentation to display selected chapters including audio-visual forms.

\section{Reflections}

No matter what communication models the subjects have chosen, the principle of "equivalence" is a vital rule. "Equivalence" is an important principle of translation, meaning the corresponding relation between the original and target text. In the communication field, there is also a concept of equivalence. Therefore, equivalence in translation-communication model goes beyond the word-to-word or sentence-to-sentence correspondence to gain new meanings. At first, the collective individuals act in concert in reference to the collectively constructed environment to gain the rights of existence, initiating its communication. Then equivalence steps in the attentions between communicator/subjects and audience. It is the attentions of both sides that decide the communication effect. The target of attention equivalence needs the re-layers' efforts. In the translation process, re-layers' performance - translators' choice of texts and translation strategies, editors' choice of the content and publishers' choice of publishing forms - constitute the attention frames. When the attention relay finishes or some degree of attention equivalence has been reached, the communication comes to the efficient category. The communication of The Book of Rites involved more than two persons and the audience did "talk back" to form a two-way conversation, laying a foundation for attention equivalence. In Legge's and Lin Yutang's time, the English speakers' attention was Chinese culture, especially the Confucianism. Legge's choice of the Four Books and Five Classics was correspondent to audience's attention. So was Lin. But the difference between Legge and Lin lied in communication forms: the former's choice of full translation was a respond to the need of English readers' full understanding of China, the latter's choice of revised selection was corespondent to English readers' 
interests. And when they found some Chinese traditional values were in conflict with their own and some application fields were far from their daily lives, they shifted their attention to the essence and the parts close to their lives. Lin's reconstruction was the version responding to such attention, which gained the utmost equivalence to the audience's attention to achieve the efficient communication. Mostly the attention equivalence is the equivalence between the need of the audience and the supply by re-layers and communicators, equivalence of views on values.

In $21^{\text {st }}$ century, the communicators having taken advantage of modern technologies, such as e-platforms and the internet, have paid attention to the task of cultural inheritance and output but neglected the audience's attention. The revised selection was the case. This version wanted to choose the content representing the essence of The Book of Rites, but the selected content failed to attract the attention and meet the need of the audience. The supply was not equal to the need or demand, which resulted in unsatisfactory communication. The retranslation, an action of message handling but not controlling, having no rights to decide the content to meet the audience's changing need, only had the right to choose the strategies to retell the same story. The concise strategy is the effort of Luo to get some equivalence to the fast pace of the time, which is not as decisive as the attention equivalence for efficient communication. Equivalence is not only a strategy, but also a phenomenon or target with different degrees from "total conductance" to "minimum conductance" [22]. Therefore, the type of equivalence and the degree of equivalence are the standards to judge the communication effect.

\section{Conclusion}

The Book of Rites represents the spirit and essence of Chinese literature and culture as the representative of Chinese classics, a collection of ancient wisdom, a reference to modern character, conduct, virtue, and education, and as a source of historical research. Beginning in the 16th century, overseas missionaries discovered that only through classical translation can the West understand a complete China. Up to now, Chinese scholars have spared no efforts to find the efficient path for communication by adjusting the classics to the times, from the original classics to the rereading and interpretation.

Although Chinese culture has been influenced by the superiority, cultural hegemony, ideology, stereotypes, prejudice and discrimination of certain ethnic groups, making Chinese classics suffering some setbacks when going out, various cultural traditions and cultural communities have gained their own discourse power and begun to develop the self-explanatory defense ability of the discourse. Therefore, the domineering culture could not deny the fact that other cultures have the ability of non-cooperation, which lays a foundation and gives a momentum for us to continue to explore the efficient communication of Chinese classics.

Xie Gang [26] has put forward some suggestions of localization of Chinese voices: using foreign tones to play
Chinese music to increase the integration and affinity of communication; using the mouth of others to speak for us to deepen the readability and credibility of communication; using others' stages for our own performance to strengthen the convenience and influence of communication. The spread of The Book of Rites needs overseas translators and sinologists to join hands with Chinese native scholars to sing the Chinese cultural songs and to convey the feelings for overseas readers, and needs the efforts of contemporary translators and scholars to perform on overseas platforms to hit the target of the maximum conductance or equivalence to realize the final aim of efficient communication.

\section{References}

[1] Song, Zhongxiu. Studies on James Legge's Translation of the Book of Rite [D]. Fujian Normal University, 2006.

[2] Huang, Qingxiu. James Legge's Translation of The Li Ki: Chinese Ancient Ritual in the Eyes of a Sinologist [D]. Fujian Normal University, 2012.

[3] Song, Zhongxiu. A Probe into James Legge's Translation of The Li Ki from the Perspective of Ideological Manipulation [J]. Journal of Kaifeng Institute of Education, 2014, 34 (11): 265-267.

[4] Song, Zhongxiu. Translation of Ancient Chinese Classic from the Perspective of Newmark Semantic Translation Theory: Legge's "Rites" Translation as a Case Study [J]. Journal of Jiamusi Vocational Institute, 2014 (12): 149-150.

[5] Xu, Bao-Feng \& Sun, Jin. On the Original and Ideal Route of Personality in The Book of Rites [A]. In Theoretical and Methodological Approaches to Social Science, Economics and Management Science. Lancaster: Destech Publication, Inc. 2015.

[6] Tang, Zhejia. The Aesthetic Education Thoughts of "The Book of Rites" on Contemporary University Education [A]. In Tang, Zhejia, Kun, Z. and Miracle J. (Eds.). Advances in Social Science Education and Humanities Research. Paris: Atlantis Press. 2018.

[7] Yao, Xinzhong. Why Does The Book of Rites Still Matter in Contemporary China? [A]. In Gu, Mingdong (Eds.). Routledge Studies in Asian Religion and Philosophy. Oxford: Routledge. 2018.

[8] Lian, Rong. Return of Chinese Etiquette Civilization and Overseas Communication: A Comparative Study of English Translation of Concept Words in The Book of Rites [J]. English Square, 2019 (04): 8-11.

[9] Li, Yuliang \& Wang, Chong. Deconstruction and Reconstruction in Translating The Li Ki by James Legge [J]. Foreign Language and Literature Research, 2019, 5 (01): 55-62.

[10] Song, Zhongxiu. An Assessment of James Legge's Translation of Culturally-Loaded Words in the Book of Rites [J]. Journal of Sanming University, 2008, 25 (3): 301-304.

[11] Song, Zhongxiu. Analysis of James Legge's Way in Dealing with Chinese Mysterious Culture in The Book of Rites [J]. Journal of Leshan Teachers College, 2012, 27 (01): 68-71. 
[12] Song, Zhongxiu. English Translation of Culturally-Loaded Words in Chinese Classics from the Perspective of Skopos Theory: English Version of James Legge's The Li Ki as a Case Study [J]. Journal of Changsha University, 2012, 26 (01): 102-104.

[13] Huang, Qingxiu. James Legge's Flexible Translation Style from the Translation of the Intermediary Word "以” in The Book of Rites [J]. 2011, 31 (1): 136-137.

[14] Fang, Meizhen. Comparative Studies on the Two English Translations of the Book of Rites [J]. Journal of Wuyi University, 2017, 36 (05): 36-38.

[15] Fang, Meizhen. English Translation of The Book of Rites from the Perspective of Functional Equivalence Theory: James Legge's and An Zengcai's Versions as Examples [J]. Journal of Shandong Agriculture and Engineering University, 2017, 34 (02): 183-184.

[16] Ji, Hongqin. A Historical Review of Chinese Cultural Classics Translation (I) [J]. Foreign Language Research, 2014 (2): 97-98.

[17] Newmark, Peter. Approaches of Translation [M]. Shanghai: Shanghai Foreign Language Education Press, 2001.

[18] Wilss, Wolfram. The Science of Translation: Problems and Methods [M]. Shanghai: Shanghai Foreign Language Education Press, 2001.
[19] Lv, Jun. Translation Studies-A Special Field of Communication Studies [J]. Foreign Languages, 1997 (2): $39-44$.

[20] Liao, Qiyi. Translation and Information Theory [J]. Journal of Sichuan International Studies University, 1997 (3): 82-86.

[21] Xie, Ke; Liao, Xueru. The Name and Nature of "Translation-Communication Theory" [J]. Shanghai Journal of Translators, 2016 (01): 14-18.

[22] Lasswell, Harold. The Structure and Function of Communication in Society [M]. He Daokuan trans. China Communication University Press, 2013.

[23] Girardot, Norman. The Victorian Translation of China: James Legge's Oriental Pilgrimage [M]. Berkeley: University of California Press, 2002.

[24] Wu, Yunhui. Modern Interpretation of The Book of Rites [M]. China Renmin University Press, 2014.

[25] Xie, Tianzhen. Translation of Literary Works May Wish to Ask for Foreign Aid [N]. Chinese Culture News, Jan. 10 $0^{\text {th }}, 2013$.

[26] Xie, Gang. The "Localized" Expression of Chinese Voice [J]. International Communications, 2016 (12): 19-21+1. 